\title{
Consumer acceptance of shared e-scooters for urban and short-distance mo- bility
}

Cristopher Siegfried Kopplin, Benedikt M. Brand, Yannick Reichenberger

\begin{abstract}
E-scooters have conquered urban areas as a means for individual mobility and compete with other modes of transportation. While some studies endorse e-scooters as eco-friendly solution for crowded cities, others report contradictory findings and highlight safety issues. To reveal factors affecting e-scooter usage from a consumer's perspective, a study using an adapted Unified Theory of Acceptance and Use of Technology (UTAUT2) is conducted. Based on random sampling among German public transportation services, 749 responses were collected and analyzed. E-scooters are studied in the context of mobility alternatives, revealing that they are mostly viewed as fun objects, and perceived safety indeed impedes their usage. Additionally, environmental concerns and individual convenience (i.e., performance expectancy) evince to represent the main drivers for using e-scooter. Besides, differences in the motivation for (potential) usage were found between owners and non-owners. Regarding the ecological assessment of e-scooters, they may, in fact, substitute walking over short distances.
\end{abstract}

\section{Introduction}

Transportation in urban environments is experiencing changes "in favor of eco-friendly, compact, and light vehicles" (Zagorskas and Burinskien`e, 2020, p. 273). E-scooters (electricityfueled scooters) have conquered cities around the world, promising a solution to the last-mile problem since their introduction in 2017 (Gössling, 2020; McKenzie, 2020; Nisson et al., 2020; Yang et al., 2020). They are discussed as alternatives to automobiles, potentially reducing traffic congestion, noise, and pollution (Che et al., 2020; Degele et al., 2018; Gössling, 2020), thereby helping to fight climate change. Early findings suggest that e-scooters are mainly used for distances between 1 and $6 \mathrm{~km}$; however, one-third of trips is even longer, which, to some extent, challenges the last-mile notion (Degele et al., 2018). Empirical evidence indicates that for these short distances, e-scooters may replace walking rather than driving (James et al., 2019; Portland Bureau of Transportation, 2018).

Apart from e-scooters' impact on the transportation system, they have also raised discussions about safety concerns and injury risks (Badeau et al., 2019; Beck et al., 2019; Kobayashi et al., 
2019; Yang et al., 2020). Previous work reports that most e-scooter users having an accident were riding without wearing a helmet (Liew et al., 2020), and providers often promote e-scooters omitting protective gear (Allem and Majmundar, 2019). Safety issues do not only concern riders themselves but have been found to affect other traffic participants, particularly pedestrians (Sikka et al., 2019). The technology has even been criticized as following the notion of "sell first, safety later" (Choron and Sakran, 2019, p. 555). Hence, it is important to include safety concerns in the examination of technology acceptance of e-scooters.

Furthermore, e-scooters are marketed as green solutions for urban traffic, even though empirical evidence supporting that claim is still scarce (Moreau et al., 2020), and results about electric vehicles illustrate a mixed picture. While recent investigations conclude that e-scooters cause slightly more $\mathrm{CO}_{2}$ emissions per kilometer compared to other modes of transportation (mainly due to their short lifespan, Hollingsworth et al., 2019; Moreau et al., 2020), others report that e-scooter usage could reduce emissions and congestion caused by automobiles (Allem and Majmundar, 2019).

To unfold their potential to reduce environmental stress, it is crucial to understand why consumers use e-scooters and how different impact factors are linked to behavioral patterns. The study at hand employs an original research model based on UTAUT2 (Venkatesh et al., 2012) to shed light on the components shaping consumers' intention to use e-scooters. In an automotive-dominated traffic setting, acceptance of novel modes is not trivial, as any alternative challenges power structures established by the dominant system (Gössling and Cohen, 2014). Previous research focused on barriers such as charging infrastructure and safety (Hardt and Bogenberger, 2019). However, demands concerning public opinion are only found in practice and lack scientific investigations (Gössling, 2020). Moreover, recent literature focused on examining electric vehicles in general or on more widespread alternatives such as e-bikes, and thereby leaving drivers and barriers for using e-scooters unanswered (Moreau et al., 2020). The study at hand seeks to address these research gaps by answering the following research question:

RQ1. What are the main drivers for consumers to use e-scooters?

Additionally, we aim to provide more granular insights on e-scooter usage, which is why the second research question is two-fold and deals with a descriptive assessment:

RQ2.1. Are e-scooters regarded as an alternative to conventional means of transportation?

RQ2.2. Is there a meaningful consumer segmentation considering utilitarian, hedonic, and sustainability-driven needs? 
To shed light on these topics, a quantitative study on technology acceptance is conducted among public transit users. Insights from the Theory of Reasoned Action (Fishbein and Ajzen, 1975; TRA, Ajzen and Fishbein, 1980) are used to link users' intention to perform a particular behavior and their actual behavior. The TRA has been used successfully in established models such as the Technology Acceptance Model (TAM, Davis, 1989) and the Unified Theory of Acceptance and Use of Technology (UTAUT, Venkatesh et al., 2003; UTAUT2, Venkatesh et al., 2012). Accordingly, we develop a model to explain consumers' e-scooter acceptance based on UTAUT2 constructs augmented with context-specific drivers for using electric vehicles. The results are then further explored using segmentation based on construct values.

The remainder of the paper is structured as follows: Section 2 provides the theoretical background, shedding light on e-scooters' role in traffic and the importance of studying technology acceptance. Section 3 describes the research design, deriving the research model and discussing the sampling strategy. Results are presented in Section 4, followed by a discussion in Section 5. The final section provides concluding remarks, addresses limitations, and highlights paths for future research.

\section{Theoretical background}

\subsection{Technology acceptance}

Technology acceptance is a mature field that has been a vivid research topic for several decades (Benbasat and Barki, 2007; Venkatesh et al., 2007), gaining rapid growth with the advent of the TAM (Davis, 1989). Originally developed to study the organizational context, it was integrated with other models to form the UTAUT (Venkatesh et al., 2003), which was later adapted for consumer settings in the form of UTAUT2 (Venkatesh et al., 2012). On a conceptual level, factors explaining technology acceptance have advanced from considering only utilitarian constructs such as perceived usefulness and perceived ease of use to include hedonic variables, which are essential for the consumer context (Nysveen, 2005; van der Heijden, 2004; Venkatesh et al., 2012). All of these models have in common that they seek to explain individuals' behavior through the formation of behavioral intentions, which in turn are influenced by a set of factors. This mechanism stems from the TRA (Fishbein and Ajzen, 1975; Ajzen and Fishbein, 1980), stating that an individual's behavioral intentions are the most immediate antecedent to actual behavior, and as such are good predictors for it. These intentions are shaped by behavioral and normative beliefs, which refer to the constructs attitude and subjective norm (Ajzen and Fishbein, 1980). As TRA was developed for settings characterized by volitional control, i.e., an individual may carry out a particular behavior if she or he likes to do so (Fishbein and Ajzen, 
1975), it is suited to explain causal relations in the consumer context of the study at hand. These constructs themselves may be influenced by a variety of factors (Fishbein and Ajzen, 1975), e.g., in TAM, perceived usefulness and perceived ease of use are postulated as factors affecting attitude (Davis, 1989). Hence, we complemented established constructs from TRA-based research with drivers and barriers identified in the context of green vehicles.

\subsection{Drivers for and ecological assessment of electric vehicles}

Motivations for using electric vehicles, such as e-scooters, are multifarious (Cordera et al., 2019; Degele et al., 2018; Haustein and Jensen, 2018; Morton et al., 2017), vary between owner and non-owner (James et al., 2019; Jenn et al., 2018; Kroesen, 2017), and differ contingent on contextual factors (Rezvani et al., 2015; Sang and Bekhet, 2015). Especially consumers with increased environmental concerns (Guerra, 2019; Kim et al., 2017; Sang and Bekhet, 2015; She et al., 2017), and those living in rural areas (Sun et al., 2020) are more likely to choose the electric vehicles. Furthermore, various socio-demographic factors affect the preference for and usage of electric vehicles in general and e-scooters in particular. For instance, Degele et al. (2018) found that consumers' gender and age affect e-scooter usage. Additionally, education, economic (Haustein and Jensen, 2018; Morton et al., 2017), consumers' innovativeness (Seebauer, 2015), social and cultural background, and prior experiences influence the preference for buying electric vehicles (Cordera et al., 2019). Dependent on the contextual framework, convenience could represent an essential motivation for using electric vehicles, e.g., when traveling in foreign cities (Fang et al., 2015; McKenzie, 2019). Apart from that, the number of charging stations and potential range to be driven with electric vehicles constitute driving forces for or against using electric vehicles (Cordera et al., 2019; Fang et al., 2015; Haustein and Jensen, 2018; Liu and Lin, 2017; She et al., 2017). As a result, this problem has meanwhile propelled research developing optimization models revealing where to find the nearest escooter to consumers (Masoud et al., 2019) or how many recharge stations are needed based on charging time (Wang, 2007). Other performance indicators affecting the decision for or against electric vehicles represent their safety, reliability, and ease of operation (Sovacool et al., 2019). Moreover, the decision for or against buying electric vehicles seems primarily driven by fuelsaving, followed by reductions in $\mathrm{CO}_{2}$ emissions and pollution (Jenn et al., 2018). Furthermore, symbolic attitudes related to conventional cars could represent a primary barrier to using electric vehicles (Haustein and Jensen, 2018). Besides, a certain degree of technology affinity facilitates using electric vehicles (Martínez-Díaz et al., 2018), as it is commonly necessary to assess map tools in the form of mobile applications for localizing and renting an available ve- 
hicle, which is then unlocked by means such as scanning QR codes (McKenzie, 2020). Additionally, other consumers' social influence and financial benefits can contribute to the acceptance of electric vehicles (Sang and Bekhet, 2015). While some studies incorporate findings related to electric vehicles in general due to the scarcity of literature on e-scooters, it still needs to be examined to what extent these insights hold for the new context: e-scooter usage evinces to be different even from its counterpart of e-bikes (McKenzie, 2019). Table 1 provides an overview of the motives for the introduction of e-scooters in urban areas. It becomes apparent that the consumer perspective lacks information.

\begin{tabular}{|c|c|}
\hline City perspective & Consumer perspective \\
\hline $\begin{array}{ll}\text { - } & \text { Reduce congestion } \\
\text { - } & \text { Reduce air pollution } \\
\text { - } & \text { Promote electric vehicles } \\
\text { - } & \text { Provide energy- and space-efficient } \\
\text { means of transportation } \\
\text { - Support commuters on their way from or } \\
\text { to transit stations }\end{array}$ & $\begin{array}{l}\text { - Fast and convenient transportation } \\
\text { - } \quad \text { Reduce } \mathrm{CO}_{2} \text { emissions }\end{array}$ \\
\hline
\end{tabular}

Table 1: Motives for e-scooter introduction. Based on Gössling (2020).

Similar to findings from the e-bike sector (Kroesen, 2017; Sun et al., 2020), politicians promote the advantages of using vehicles with lower emission rates per kilometer for gaining approval rates among more sustainable-oriented citizens. Besides, findings about electric vehicles provide a dialectical picture concerning their actual benefits for the environment. While some authors find e-scooters to induce more $\mathrm{CO}_{2}$ emissions compared to previous alternatives due to their short lifespan (Hollingsworth et al., 2019; Moreau et al., 2020), others highlight less pollution of electric two-wheelers compared to cars and motorcycles (Cherry et al., 2009; Weiss et al., 2015) or positive net effects for the environment by e-bike usage (Kroesen, 2017; Sun et al., 2020) and electric vehicles in general (Zagorskas and Burinskien`e, 2020). Although research draws mixed findings about e-scooters ecological assessment, politicians still subsidize e-scooter purchases and try to replace fossil oil-driven vehicles (Pham et al., 2019).

In contrast to these driving forces of e-scooter adoption, multiple studies reveal a heightened amount of traffic crashes caused by e-scooters (Choron and Sakran, 2019; Kobayashi et al., 2019; Nisson et al., 2020). These accidents do concern both pedestrians (Sikka et al., 2019) as well as e-scooter riders themselves (Nisson et al., 2020), resulting in increased irritation of pedestrians facing the risk of e-scooters on footpaths (Che et al., 2020; James et al., 2019). As a result, literature started to analyze types of crashes caused by e-scooters based on demographics 
(Liew et al., 2020; Yang et al., 2020), speed and angle of e-scooters within crashes (Xu et al., 2016), type of injury (Badeau et al., 2019; Beck et al., 2019; Puzio et al., 2020) and manufacturers' emphasis on wearing protective gear (Allem and Majmundar, 2019). In line with these findings, research revealed safety to represent one of the major barriers preventing consumers from buying electric vehicles (She et al., 2017). Issues that occurred rather unexpected are those of vandalism, short e-scooter lifetime, and recycling and disposal (Gössling, 2020). Besides, the literature reveals the opportunistic driving behavior of e-scooter users that are not shirking back from violating traffic rules (Tuncer et al., 2020).

\section{Research design}

Perceptions of responsibility for preserving the environment and avoiding ecological damage are integrated into the model via the environmental concerns construct. As e-scooters are marketed as an eco-friendly mode of transportation, a positive influence on intention to use is expected. Concerning behavioral beliefs, performance expectancy is employed to capture utility, i.e., extrinsic motivation, and hedonic motivation complements the model through integration of intrinsic motivation (van der Heijden, 2004; Venkatesh et al., 2012), and are expected to increase consumers' intention to use e-scooters. Effort expectancy refers to "the degree of ease associated with consumers' use of technology" (Venkatesh et al., 2012, p. 159) and is postulated to have a positive effect on intention to use. Facilitating conditions, acting as a proxy for behavioral control in UTAUT and UTAUT2 and as such corresponding to TRA's successor, the Theory of Planned Behavior (Ajzen, 1991; Venkatesh et al., 2012), is dropped from the framework, as our model relying on TRA assumes that consumers have complete control of their decision to use e-scooters. Hence, our model implicitly adopts the view that individuals' behavior of using (or not using, respectively) e-scooters in traffic is volitional. Normative influences as postulated in TRA are captured by the social influence construct, replacing/advancing subjective norms from the TRA model, which are presumed to yield a positive impact on intention to use (Venkatesh et al., 2003). In the context of e-scooters, risks of accident and injury have been a significant topic of study (Badeau et al., 2019; Beck et al., 2019; Kobayashi et al., 2019; Yang et al., 2020). Consequently, consumers' perception of being at risk while using an e-scooter is included as a moderator variable and hypothesized to decrease intrinsic motivation. Summarizing the assumptions derived by literature, Fig. 1 depicts the resulting research model. We therefore hypothesize: 


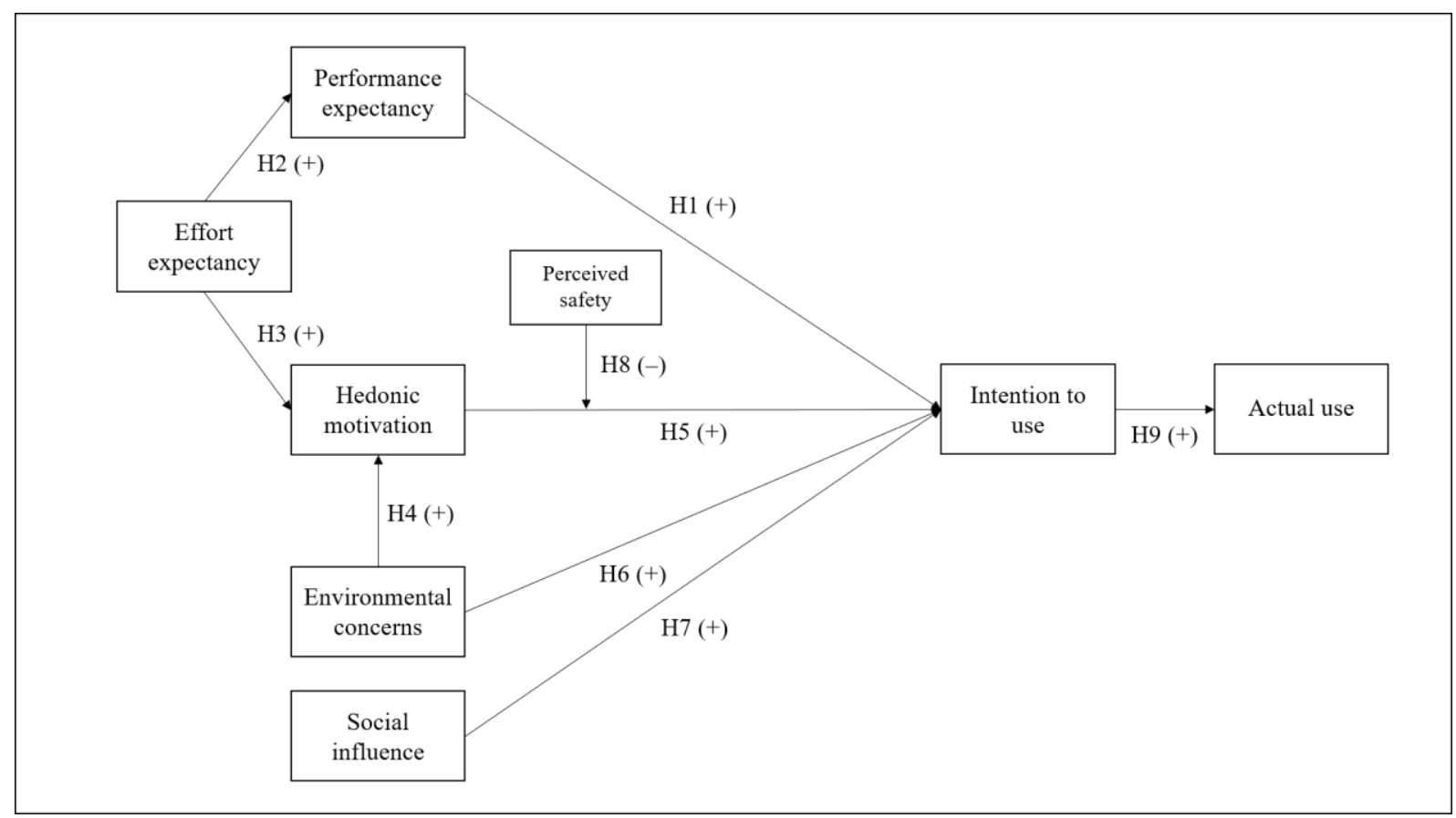

Figure 1: Research model and hypothesis.

All items were measured on a seven-point Likert-type scale ranging from 'I completely disagree' (i.e., 1) to 'I completely agree' (i.e., 7). Construct scales were adapted from extant literature to ensure validity (see Appendix A). Items for performance expectancy, effort expectancy, hedonic motivation, social influence, intention to use, and actual use are adapted from UTAUT2 (Venkatesh et al., 2012). Environmental concerns are adapted from Dunlap et al. (2000) and Lee (2008), and perceived safety is based on Osswald et al. (2012). Following demands regarding the measurement of actual use in previous research (Burton-Jones and Straub, 2006; see, e.g., Benbasat and Barki, 2007; Sun, 2012), in addition to the frequency of use, which was also measured on a seven-point scale ranging from 'never' to 'several times a day', different aspects such as travel distance, the substitution of other transportation modes, and destination were included in the survey.

Following sampling strategies proposed by the extant literature (Permut et al., 1976; Singh and Matsuo, 2004), we focused on public transportation services in Germany derived from topicrelated standard references, such as members of the the Association of German Transport Companies (VDV), to forward our survey and reach out to individual consumers. These members were contacted and asked to spread the questionnaire through their Facebook social media channel. This approach reduces the need for comprehensive sample specifications (Permut et al., 1976). As e-scooters are purposed to close the last mile gap, VDV members focused on railway transportation $(n=158)$ and merely providing infrastructure $(n=16)$ were excluded. Individuals 
only focusing on railway-related information are deemed different compared to consumers interested in local traffic: a mere focus on railway is assumed to belong to individuals that are reliant on this alternative, e.g., because they need to commute over far distances frequently, and thus, are less committed to local traffic than road users particularly following this type of content. Those who engage in content on railway and other transportation modes - and, consequently, also received information from other VDV members - may be reached via our sample strategy. Out of 608 organizations, 450 remained as potential contacts. After removing duplicates corresponding to different federal states, 431 organizations were identified for contacting (VDV, 2020). We then detached those not possessing a Facebook page and having their page set up at the moment $(n=323)$.

Consequently, 92 VDV members were selected, of which 57 cooperated and disseminated the survey (see Appendix B). Control variables in the survey were used to trace how a respondent entered the survey (i.e., through which channel) to remove duplicates if necessary and get an impression of the questionnaire's dissemination. As the study at hand is the first to address consumer acceptance of e-scooters using a quantitative approach, there is no empirical data to base sample size estimation. Hence, the rule of thumb following the inverse square root method proposed by Kock and Hadaya (2018) for PLS models is used to determine the minimum sample size, suggesting at least 160 observations.

\section{Results}

\subsection{Descriptive statistics}

Data collection took place over five weeks in November and December 2019. Among the noncooperative organizations, no specific pattern regarding geographical location and city size could be found. In total, 1,185 participants initiated the survey. After removing incompletes ( $\mathrm{n}$ $=414)$ and checking for speeders and straightliners $(\mathrm{n}=22), 749$ questionnaires were retained for analysis. All respondents accessed the survey via Facebook as intended, and no duplicates needed to be removed. Non-response bias was addressed by comparing the first respondents to the last ones, assuming that late respondents act similar to non-respondents (Armstrong and Overton, 1977; Ferber, 1948). Respondents from the first quartile were compared to participants from the last quartile using a series of t-tests, revealing no significant results. These findings were further corroborated by calculating a multi-group analysis (MGA) to compare the PLS model of the first quartile to the model of the last quartile. Again, no differences were found. Hence, it is assumed that non-response bias does not play a critical role in our study. Regarding 
the distribution of the survey, 562 respondents entered the survey through a public transportation services' social media channel, 26 came from social media accounts dealing with transportation in general, and 22 accounts dedicated to e-scooters. Five participants were recruited from e-scooter providers' social media accounts. Additional 134 respondents did not indicate how they entered the survey. Age ranged from 18 to 73 years, with an average of 34.35 (median = 32 ) and a standard deviation of 11.49 years (lower quartile $=25$, upper quartile $=41$ ). More than one-third of the participants were female (31.8\%). Almost half of the respondents have experience in using an e-scooter (46.6\%), most of them being practiced users with a usage pattern exceeding ten rides $(15.1 \%)$, others having tested a vehicle for once $(10.0 \%)$, or used it two to three times (9.1\%). 9.7\% remarked they possess an e-scooter. A correlation analysis was performed to examine the relationship between a participant's residence (ranging from rural to major city above a population of 100,000) and his or her intention to use e-scooters, finding a weak negative link (Kendall $\tau=-0.116, p<0.001$ ). No correlation between intention to use and age could be found $(r=0.100, p=0.779)$.

At the end of the survey, participants were asked whether they had additional remarks. In general, participants seem to be well-informed about the topic, and e-mobility and environmental aspects on an overall level. Annotations targeted safety conflicts between e-scooter riders and other road users $(n=36)$, the negative environmental impact of e-scooter production and usage $(n=28)$ stating that over their lifespan, they rather cause harm than benefits, and the social aspect of so-called 'juicers' that collect and charge e-scooters $(n=4)$.

In addition, participants using e-scooters reported on their last e-scooter ride and were asked to indicate which alternative mode of transportation was superseded. The most substantial decrease was found for walking (mentioned by $31.4 \%$, one-sample t-test: $\mathrm{T}=-19.524, \mathrm{p}<0.001$ ), followed by bus $(14.4 \%, \mathrm{~T}=-8.160, \mathrm{p}<0.001)$, streetcar or metro $(14.4 \%, \mathrm{~T}=-5.422, \mathrm{p}<$ 0.001; however, note that not all German cities offer these alternatives $)$, and car $(8.1 \%, \mathrm{~T}=-$ $11.449, \mathrm{p}<0.001)^{1}$.

Lastly, e-scooters' potential to replace car trips was investigated. Participants were given examples of different travel distances, ranging from short trips under $2 \mathrm{~km}$ and mid-range trips (2 to $5 \mathrm{~km}$ ) to long-range distances (more than $5 \mathrm{~km}$ ). Respondents were asked to indicate their willingness to use an e-scooter for the respective travel distance on a seven-point Likert-type scale $(1=$ 'I completely disagree', 7 = 'I completely agree').

\footnotetext{
${ }^{1}$ One-sample t-tests were used to assess our empirical distribution's deviation from indifference, which assumes a mean value of 3 on a five-point Likert-type scale.
} 


\begin{tabular}{|c|c|c|c|c|c|}
\hline Challenges & Tendency & Total & $\begin{array}{l}\text { E-scooter } \\
\text { owners } \\
(n=73)\end{array}$ & $\begin{array}{l}\text { Non-owners } \\
(\mathrm{n}=676)\end{array}$ & $\begin{array}{l}\text { Mann-Whitney- } U \text { - } \\
\text { test } \\
\text { t-value (p-value) }\end{array}$ \\
\hline \multirow[t]{3}{*}{ Air pollution } & Agree & 18.7 & 43.8 & 15.9 & $7.660(<0.001)$ \\
\hline & Rather agree & 26.7 & 31.5 & 26.2 & \\
\hline & Rather disagree & 23.9 & 12.3 & 25.1 & \\
\hline Median $0 .=2$ & Disagree & 22.4 & 4.1 & 24.4 & \\
\hline Median n.-o. $=3$ & Not sure & 8.3 & 8.2 & 8.3 & \\
\hline \multirow[t]{3}{*}{ Congestion } & Agree & 15.2 & 43.8 & 12.1 & $9.190(<0.001)$ \\
\hline & Rather agree & 27.1 & 35.6 & 26.2 & \\
\hline & Rather disagree & 24.6 & 12.3 & 25.9 & \\
\hline Median $0 .=2$ & Disagree & 22.3 & 2.7 & 24.4 & \\
\hline Median n.-o. $=4$ & Not sure & 10.8 & 5.5 & 11.4 & \\
\hline \multirow{3}{*}{$\begin{array}{l}\text { Lack of space for } \\
\text { parking }\end{array}$} & Agree & 21.2 & 54.8 & 17.6 & $13.648(<0.001)$ \\
\hline & Rather agree & 29.5 & 38.3 & 28.5 & \\
\hline & Rather disagree & 20.3 & 2.7 & 22.2 & \\
\hline Median $0 .=1$ & Disagree & 21.9 & 1.4 & 24.1 & \\
\hline Median n.-o. $=3$ & Not sure & 7.1 & 2.7 & 7.5 & \\
\hline \multirow[t]{3}{*}{ Accidents } & Agree & 5.5 & 8.2 & 5.2 & $7.358(<0.001)$ \\
\hline & Rather agree & 4.4 & 13.7 & 3.4 & \\
\hline & Rather disagree & 26.2 & 35.6 & 25.1 & \\
\hline Median o. $=3$ & Disagree & 51.8 & 9.6 & 56.4 & \\
\hline Median n.-o. $=5$ & Not sure & 12.1 & 32.9 & 9.9 & \\
\hline \multirow[t]{3}{*}{ Traffic volume } & Agree & 8.3 & 17.8 & 7.2 & $6.956(<0.001)$ \\
\hline & Rather agree & 18.4 & 43.8 & 15.7 & \\
\hline & Rather disagree & 27.4 & 17.8 & 28.4 & \\
\hline Median o. $=2$ & Disagree & 28.6 & 6.8 & 30.9 & \\
\hline Median n.-o. $=4$ & Not sure & 17.4 & 13.7 & 17.7 & \\
\hline \multirow[t]{3}{*}{ Noise pollution } & Agree & 22.6 & 56.2 & 18.9 & $7.655(<0.001)$ \\
\hline & Rather agree & 31.2 & 28.8 & 31.5 & \\
\hline & Rather disagree & 17.5 & 4.1 & 18.9 & \\
\hline Median o. $=1$ & Disagree & 18.4 & 6.8 & 19.7 & \\
\hline Median n.-o. $=2$ & Not sure & 10.3 & 4.1 & 10.9 & \\
\hline Public transport & Agree & 15.5 & 39.7 & 12.9 & $6.683(<0.001)$ \\
\hline \multirow[t]{2}{*}{ shortcomings } & Rather agree & 29.4 & 35.6 & 28.7 & \\
\hline & Rather disagree & 18.6 & 6.8 & 19.8 & \\
\hline Median o. $=2$ & Disagree & 24.3 & 9.6 & 25.9 & \\
\hline Median n.-o. $=3$ & Not sure & 12.3 & 8.2 & 12.7 & \\
\hline
\end{tabular}

Table 2: Challenges addressed by e-scooters. Values in percent. o. = owners, n.-o. = non-owners. 
Short distances were evaluated rather favorably (mean $=4.24, \mathrm{SD}=2.18$ ), followed by midrange $($ mean $=3.65, \mathrm{SD}=2.07)$, and long-range distances $($ mean $=2.61, \mathrm{SD}=1.77)$. A onesample t-test revealed that all three assessments were significantly different from indifference on a 0.05 (short distance) and 0.01 level (mid-range and long-range); albeit, they point in opposite directions. While short distances were evaluated as rather attractive for e-scooter usage, mid- and long-range distances were rated unattractive. However, standard deviations indicate that participants were rather discordant.

\subsection{Outer model evaluation}

For estimating the main model, a structural equation modeling using partial least squares (PLSSEM) was employed. The algorithm was set to path weighting, a maximum of 300 iterations, and a stop criterion of $10^{-7}$, and converged after five iterations. Following the established twostep approach, the outer model and measurement model, respectively, are assessed. Outer loadings are evaluated using a threshold of 0.708 (Hair et al., 2019), revealing that three indicators fall short of this value: EE3 (0.689), EE4 (0.621), and SI4 (0.627; see Appendix A). In order to decide whether to keep these in the model, internal consistency measures are consulted. Composite reliability (Jöreskog, 1971) and average variance extracted (AVE) are used as a reference; however, Cronbach's $\alpha$ is also provided due to the measure's high profile. Table 3 displays the results, showing satisfactory values. Hence, to ensure theoretical rigor, the indicator triad below the outer loadings threshold are retained.

\begin{tabular}{lccccc}
\hline Latent variable & Indicators & Mean (SD) & Cronbach's $\alpha$ & CR & AVE \\
\hline Performance expectancy & 4 & $3.65(1.81)$ & 0.909 & 0.936 & 0.785 \\
Effort expectancy & 4 & $5.67(0.98)$ & 0.753 & 0.845 & 0.582 \\
Hedonic motivation & 3 & $4.51(1.60)$ & 0.911 & 0.944 & 0.848 \\
Environmental concerns & 3 & $2.71(1.55)$ & 0.888 & 0.931 & 0.818 \\
Social influence & 4 & $2.71(1.29)$ & 0.822 & 0.883 & 0.659 \\
Perceived safety & 4 & $4.13(0.91)$ & 0.875 & 0.913 & 0.725 \\
Intention to use & 4 & $3.09(1.97)$ & 0.942 & 0.959 & 0.854 \\
Actual use & 1 & $5.52(1.86)$ & \multicolumn{3}{c}{ Single-indicator construct } \\
\hline Table 3: Construct assessment. & & \multicolumn{3}{c}{}
\end{tabular}

For evaluation of discriminant validity, the Fornell-Larcker criterion (Fornell and Larcker, 1981), an assessment of cross-loadings, and evaluation of the heterotrait-monotrait ratio (HTMT, Henseler et al., 2015) is employed. Table 4 summarizes HTMT examination; FornellLarcker is provided in Appendix C. Examination of cross-loadings confirms that all indicators load highest on the latent variable they are assigned to. 


\begin{tabular}{lrrrrrrrr}
\hline & PE & EE & HM & EC & SI & PS & ITU & AU \\
\hline PE & & & & & & & \\
EE & 0.547 & & & & & & \\
HM & 0.744 & 0.520 & & & & & \\
EC & 0.825 & 0.396 & 0.657 & & & & \\
SI & 0.797 & 0.476 & 0.651 & 0.887 & & & \\
PS & 0.580 & 0.570 & 0.478 & 0.518 & 0.498 & & \\
ITU & 0.895 & 0.551 & 0.736 & 0.845 & 0.824 & 0.612 & \\
AU & 0.717 & 0.437 & 0.536 & 0.677 & 0.672 & 0.516 & 0.848 \\
\hline
\end{tabular}

Table 4: HTMT ratios.

Two dyads exceed the conservative threshold of 0.85 , but still meet the upper limit of 0.90

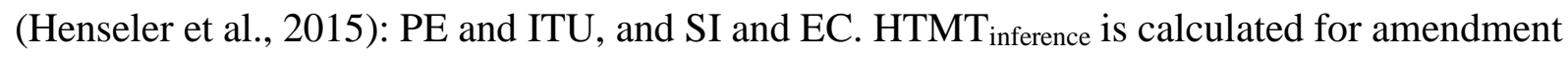
using bootstrapping with 10,000 subsamples, revealing that the null value of 1 is excluded from 95\% confidence intervals, and hence overall, discriminant validity is verified.

\subsection{Inner model evaluation}

To check the model for collinearity issues and common method bias, variance inflation factors (VIFs) are employed, using a threshold of 3.3 (Kock, 2015; Hair et al., 2019). All VIFs meet this criterion; hence an absence of both collinearity problems and common method bias can be assumed. The inner model is examined drawing on determination coefficients, cross-validated redundancy, and bootstrapping to investigate the path coefficients' statistical significance (Hair et al., 2011). For moderator analysis of perceived safety, an orthogonalization approach was used (Henseler and Chin, 2010). Findings are summarized in Fig. 2, and an assessment of explanatory and predictive power is provided in Table 5.

\begin{tabular}{lccrcr}
\hline Construct & $\mathrm{R}^{2}$ value & Adjusted $\mathrm{R}^{2}$ value & \multicolumn{1}{c}{ Evaluation } & $\mathrm{Q}^{2}$ value & Evaluation \\
\hline PE & 0.205 & 0.204 & Weak & 0.158 & Small relevance \\
$\mathrm{HM}$ & 0.420 & 0.418 & Weak to moderate & 0.350 & Medium relevance \\
ITU & 0.789 & 0.787 & Substantial & 0.666 & Large relevance \\
AU & 0.680 & 0.680 & Moderate & 0.675 & Large relevance \\
\hline
\end{tabular}

Table 5: Inner model assessment. Evaluation based on Hair et al. (2019). 


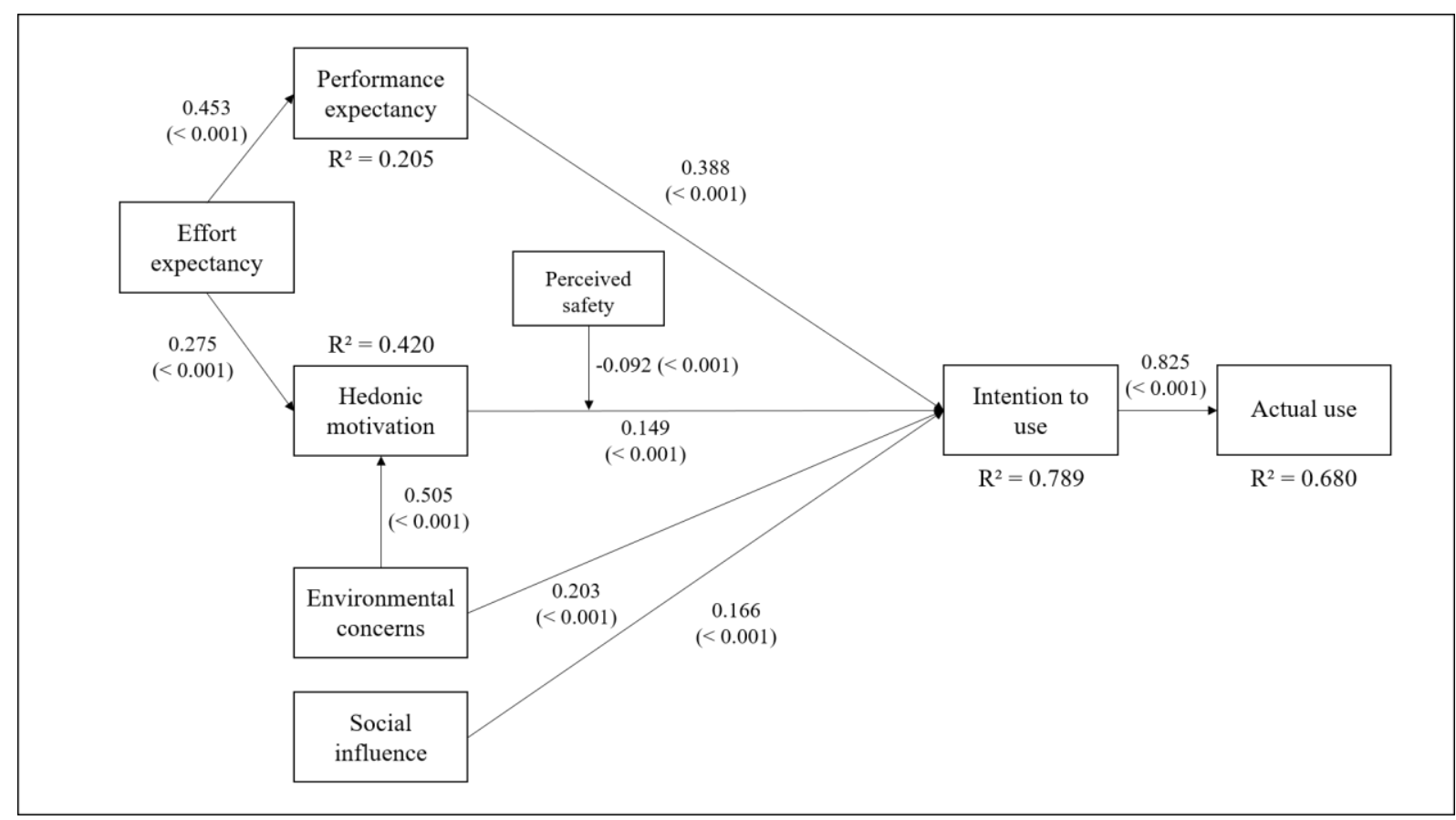

Figure 2: Inner model results.

All proposed hypotheses could be corroborated. EE, as an antecedent of PE and HM, has a more substantial positive impact on PE than on HM. Its variance explanation for PE is slightly below the 'weak' threshold of 0.25 (Hair et al., 2019), indicating that EE does not suffice to explain consumers' PE. This result is consistent with our theoretical derivation of the model postulating that PE is an important and self-contained factor. PE indeed exhibits the most substantial link to ITU in the model. Hedonic motivation yields an $\mathrm{R}^{2}$ value of 0.420 , which approaches the 'moderate' benchmark of 0.50 (Hair et al., 2019). While it is influenced by EE, indicating that ease of use increases enjoyment, a much stronger impact was found for EC (path coefficient = 0.505). Participants' ecological reflections appear to be positively linked to the joy derived from e-scooter usage. SI as a depiction of subjective norm (Fishbein and Ajzen, 1975), i.e., the perception of being under pressure due to social standards, has a reasonably weak positive impact on ITU. Additionally, PS was confirmed to serve as a moderator of the effect of HM on ITU, although its impact is rather weak. Interestingly, a direct effect of PS on ITU was detected, which is stronger than the moderating effect (path coefficient $=-0.125, \mathrm{p}<0.001$ ). Regarding ITU's variance explanation, the proposed set of factors provided substantial explanatory power $\left(\mathrm{R}^{2}=0.789\right)$. For the relation of ITU and AU, a tight positive link was found (path coefficient $=0.825)$, which is an interesting finding in the context of sustainability, as in many cases, the gap between ITU and AU is a major challenge (Hughner et al., 2007; Kollmuss and Agyeman, 2002; Pickett-Baker and Ozaki, 2008). Our result indicates that the causal relation is symmetric in the context of e-scooters, i.e., high values of ITU elicit AU, and low values of ITU lead to the absence of use behavior (Woodside, 2013). 
In order to provide deeper insights, we also collected participants' motives for using an escooter. Here, we asked respondents why they trialed e-scooters previously. Out of the 749 respondents, 349 had used an e-scooter before. 39 (11.7\%) indicated they wanted to save money by avoiding bus and train tickets, 349 (100\%) answered using an e-scooter seemed enjoyable, and $58(16.6 \%)$ mentioned they deemed e-scooters to be eco-friendly. Further, $81(23.2 \%)$ indicated a social aspect and used an e-scooter to ride with their friends, while 64 (18.3\%) sought to avoid looking for a parking lot, and 85 (24.3\%) responded they had no car. Another 75 participants $(21.5 \%)$ mentioned the lack of a bus or train station at their destination, and 259 (74.2\%) emphasized the utility of moving fast and effortless.

\subsection{Multi-group analyses}

For further insights, several segments are defined and used for MGA (Henseler, 2012; Sarstedt et al., 2011). Multiple authors find that the acceptance and usage of electric vehicles depend on consumers' attitudes towards the environment (Guerra, 2019; Kim et al., 2017; Rezvani et al., 2015; Sang and Bekhet, 2015). Therefore, the data set is split by participants' environmental concerns in the first step. The construct was assessed employing a seven-point Likert-type scale, which is used for segmentation. The group of 'environmentally concerned users' consists of cases with ratings above $4(n=426)$, and the group of 'environmentally unworried users' comprises cases with ratings below $4(n=281)$. Cases yielding the neutral value of 4 were excluded due to indecisiveness $(n=42)$. Results mirror findings from the total sample. A difference was detected for the relation of $\mathrm{EE}$ and $\mathrm{PE}$, which is moderate and positive for both segments, but significantly higher for the environmentally concerned group (path coefficients 0.492 versus 0.255 , difference $0.238, \mathrm{p}<0.001$ ). An alternative calibration omitting observations yielding values of 3, 4, and 5 was considered; however, the segment size for environmentally concerned users turned out to be too small for calculation $(n=28)$. On the other hand, an overwhelming majority was assigned to the unworried segment $(n=439)$.

Drawing on findings from Table 2, e-scooter owners and non-owners were employed for a second segmentation, as literature highlighted differences among these groups (James et al., 2019). Several insights may be obtained from MGA (Table 6). Observing models for owners and nonowners separately, all hypotheses are corroborated for the non-owner segment. PE has the strongest positive impact on ITU (path coefficient $=0.393$ ), followed by EC (path coefficient $=0.212$ ). EC further impact HM to a remarkable extent (path coefficient $=0.480$ ) and PS yields a negative moderating effect on the relation between HM and ITU. In the case of owners, several hypotheses are rejected. PE does not appear to be a driver of ITU, and EE could not be 
found to influence HM. Strikingly, findings suggest that for owners, EC do not play a role for ITU at all (path coefficient $=-0.016, p=0.921$ ), and no convincing evidence for a moderating effect of PS was found (path coefficient $=-0.136, p=0.467$ ). Moreover, compared to nonowners, the link between ITU and AU is much weaker (path coefficients: 0.324 versus 0.763 ). This result indicates that for owners, additional factors not included in the model may have an important impact. Differences between the models show a convergence of PLS-MGA and parametric test results. Significant discrepancies were identified for the EC-HM relation and the link between ITU and AU. Hence, owners and non-owners indeed differ regarding the impact of EC on HM, which is negligible for owners, and the strength of the ITU-AU path.

\begin{tabular}{|c|c|c|c|c|c|c|}
\hline \multicolumn{4}{|c|}{ Hypotheses } & \multicolumn{2}{|c|}{ Path coefficients (p-value) } & \multirow{2}{*}{$\begin{array}{c}\text { Difference } \\
\text { (p-value PLS-MGA, p- } \\
\text { value parametric test) }\end{array}$} \\
\hline & & & & $\begin{array}{l}\text { Owners } \\
(\mathrm{n}=73)\end{array}$ & $\begin{array}{c}\text { Non-Owners } \\
(\mathrm{n}=676)\end{array}$ & \\
\hline H1 & $\mathrm{PE}$ & $\rightarrow$ & ITU & $0.197(0.102)$ & $0.393(<0.001)$ & $0.207(0.072,0.082)$ \\
\hline $\mathrm{H} 2$ & $\mathrm{EE}$ & $\rightarrow$ & $\mathrm{PE}$ & $0.345(0.014)$ & $0.415(<0.001)$ & $0.116(0.307,0.259)$ \\
\hline $\mathrm{H} 3$ & $\mathrm{EE}$ & $\rightarrow$ & HM & $0.109(0.484)$ & $0.282(<0.001)$ & $0.188(0.144,0.086)$ \\
\hline $\mathrm{H} 4$ & EC & $\rightarrow$ & HM & $0.264(0.034)$ & $0.480(<0.001)$ & $0.230(0.036,0.010)$ \\
\hline H5 & HM & $\rightarrow$ & ITU & $0.262(0.047)$ & $0.152(<0.001)$ & $-0.107(0.405,0.236)$ \\
\hline H6 & $\mathrm{EC}$ & $\rightarrow$ & ITU & $-0.016(0.921)$ & $0.212(<0.001)$ & $0.200(0.101,0.096)$ \\
\hline $\mathrm{H} 7$ & SI & $\rightarrow$ & ITU & $0.313(<0.001)$ & $0.169(<0.001)$ & $-0.161(0.108,0.122)$ \\
\hline H8 & PS* & $\rightarrow$ & $\mathrm{HM} \rightarrow \mathrm{ITU}$ & $-0.136(0.467)$ & $-0.081(<0.001)$ & $0.097(0.492,0.314)$ \\
\hline H9 & ITU & $\rightarrow$ & $\mathrm{AU}$ & $0.324(0.014)$ & $0.763(<0.001)$ & $0.444(<0.001,<0.001)$ \\
\hline
\end{tabular}

Table 6: Multi-group analysis for owners and non-owners. *Moderating effect.

\section{Discussion}

Data analysis revealed that about half of the sample had used an e-scooter before. Descriptive statistics show that, unsurprisingly, e-scooter owners and non-owners differ in their perception of benefits. More than half of e-scooter owners view the vehicles as remedies for lack of parking space and noise pollution, followed by about $40 \%$ who see positive effects for air pollution, congestion, and shortcomings of public transportation. Non-owners are rather undetermined; however, they agree on positive impacts on noise pollution, but at the same time, they expect a high accident hazard. An important question is raised by Gössling (2020), asking whether trips using e-scooters replace trips otherwise using motorized vehicles or cycling and walking. The answer to this question appears to be critical on the future success of e-scooters, regarding high 
expectations concerning their positive influence on traffic, and climate in general. As a multiplicity of providers competes in the market, employing large amounts of venture capital to thrive for growth (Gössling, 2020), misjudgment of consumer perception poses the threat of high financial losses. This beauty spot on e-scooters' proclaimed sustainability image is further corroborated by the advent of tenuous jobs such as collecting and charging vehicles, commonly using workers' private accommodation. While approaches supporting these jobs in locating escooters exist (see, e.g., Masoud et al., 2019), the actual issue is how these concepts promoting the gig economy fit the notion of a triple bottom line of sustainability with social aspects as one of the key elements (Elkington, 1998). Our findings add to these concerns.

Respondents indicated that their last trips replaced walking rather than motorized transportation, and when asked about future rides, this pattern was repeated. This result of e-scooters being used for comfort rather than for environmental reasons is consistent with the public opinion in Germany: one of the major concerns regarding traffic is gridlocks due to constantly increasing traffic volume (GfK, 2019), and e-scooters provide an individual solution that is independent of regular roadways. Further, consumers viewing e-scooters as effective means for environmental production comprise merely $20 \%$ of road users (YouGov, 2019). Our results show that e-scooters may replace walking rather than other means of transportation; however, they have a slight impact on bus, car, and streetcar/metro usage as well.

Particularly investigating e-scooters' potential to supersede cars across various distances, participants exhibited a slight tendency to swap cars for e-scooters over short distances $(<2 \mathrm{~km})$; however, for longer trips, the opposite was mentioned. Hence altogether, only weak evidence for e-scooters' potential to replace motorized vehicles in the urban area was found, and consumers may rather abandon walking instead of other modes of transportation. While e-scooters are generally perceived as an eco-friendly transportation solution, the modes of transportation superseded indicate a negative environmental net effect. Hence, politicians should be aware of the aggregated harmful effects of e-scooters on the environment and, therefore, rethink their policy of incentivizing e-scooters. Besides, these findings emphasize convenience as a crucial driver for using e-scooters (Fang et al., 2015). Moreover, we contribute to electric transportation research by validating prior findings derived from electric vehicles (Sovacool et al. 2019) for e-scooters. Accordingly, ease of operation, reliability, and environmental concerns represent important drivers not only for electric vehicle adoption, but also for e-scooters. As the adoption of electronic vehicles can vary contingent on cultural background (Cordera et al. 2019), we further extend current literature by verifying occurring effects found in China (Sovacool et al. 2019) among German consumers. 
Regarding results from PLS-SEM, performance expectancy was found to be the strongest predictor for intention to use, followed by environmental concerns. Social influence and hedonic motivation yield relatively weak, but significant, positive impacts. Intention to use was found to be a good predictor for actual use (path coefficient $=0.825$ ), which indicates that there are little to no barriers that may hamper translating intentions into actions, and which confirms our research model's implicit assumption of volitional behavior. This is rather remarkable, as many studies in the context of sustainability suffer from the attitude/behavior or intention/behavior gap, respectively. For e-scooters, this challenge does not seem to apply, confirming that the research model is sufficiently powerful to explain both consumers' intention to use e-scooters and their actual use behavior. In part, this result may stem from the sampling approach, which captured fairly informed road users. These individuals might yield higher awareness of transportation alternatives than the general public and, as such, may be assumed to possess a firmer opinion on their benefits and detriments. Hence, the strong positive correlation between intention and actual behavior may be, at least partially, a result of this informed opinion and its implementation. For consumers less involved in modes of transportation, this correlation is assumed to diminish. Moreover, as the participants constitute of Facebook users, they could be considered as rather young consumers and thus, yield higher environmental concerns compared to older ones (Tait et al., 2020; Yadav and Pathak, 2016). Consequently, environmental concerns' positive influence on HM and ITU may potentially be overestimated.

From a TRA point of view, findings show that relevant factors for behavioral and normative beliefs have been identified. Cross-validation added several interesting insights. First and foremost, while PLS-SEM revealed hedonic motivation to play a relatively small role in forming the intention to use, participants stated that e-scooters have a strong appeal of entertainment and that this appeal is an important motivation to undertake an e-scooter trip. The reason why HM serves as a more important driver for ITU among owners compared to non-owners (Table 6) might be due to the 'greener' perception of using e-scooter from the owners' perspective (Table 2). This effect (i.e., consuming green products resulting in enhanced enjoyment experience using it) has recently been described as 'green consumption effect' (Tezer and Bodur, 2019).

The role of environmental concerns exhibited surprising results: segmentation of e-scooter owners and non-owners displayed that while for non-owners, environmental concerns have a positive influence on intention to use, this effect was absent for owners. For them, hedonic motivation had a more substantial impact on intention to use than for non-owners. The influence 
of normative beliefs, i.e., social influence, did not differ depending on the degree of participants' environmental concerns; however, a difference was found between owners (higher impact, path coefficient $=0.313$ ) and non-owners (lower impact, path coefficient $=0.169)$. Regarding perceived safety risk, owners and non-owners exhibited differences in the way that owners evaluate risk lower (owners: mean $=3.98, \mathrm{SD}=0.85$, non-owners: mean $=4.22, \mathrm{SD}=$ 0.90, t-test: $\mathrm{p}<0.001)$. However, it is important to note that we do not have information about the causal direction, i.e., it is not clear whether e-scooter ownership and, as such, familiarity with the vehicle elicit perceptions of lower risk, or consumers yielding low-risk perception are more willing to buy an e-scooter and become part of the owner segment. Considering the absolute magnitude, perceived risk was assessed rather neutral. This is an important finding, as the objective risks have been vividly discussed in the literature, and injuries are a serious threat, made especially clear by the expression "sell first, safety later" (Choron and Sakran, 2019, p. 555). Particularly against the backdrop of many e-scooter providers' marketing regularly showing riders without protective gear, it becomes clear that the necessity of protection needs to be pointed out both by e-scooter providers and by policymakers. The two principal options to do so are fining riders participating in traffic without adequate protective equipment, and interdicting advertisements that show situations conflictive with real-world traffic requirements.

Besides findings from our research model, we additionally asked about motives for trying escooters in the past. Here, participants indicated that riding an e-scooter seemed enjoyable (both when riding alone and with friends) and providing utilitarian benefits in terms of not having to search for a parking lot, saving money for bus and metro tickets, and offering mobility when lacking access to a vehicle. While in general, these findings confirm the results from our PLS model, the importance of hedonic motivation appeared to be the primary reason for trying out an e-scooter but does not play a major role in the perception of using e-scooters. A straightforward explanation for that finding would be that participants did not enjoy their ride as expected, and as such, evaluate entertainment low, or simply were curious about trying out an e-scooter.

Concerning the structural model, high (but acceptable) HTMT ratios for PE and ITU, and SI and EC, respectively, were identified. From a discriminant perspective, this opens the possibility of discussing EC as being perceived as similar to SI by consumers, e.g., in terms of feeling pressured by peers or gaining the impression that EC are socially desirable and externally imposed. Hence, the acceptance of e-scooters by peers can serve as a light catalyst for other consumers. In contrast to research exploring the acceptance of electric vehicles in general (such as Jenn et al., 2018), literature needs to be extended by hedonic motivation when examining escooter motives. Additionally, the previous finding derived from e-bike usage on a tendency to 
favor electric transport solutions when living in rural areas (Sun et al., 2020) could not be confirmed for e-scooters. Besides, we contribute to current literature dealing with e-scooter related accidents by empirically analyzing the effect of perceived safety and how it decreases intention to use. An important practical implication in order to decrease the number of e-scooter related accidents lies in the promotion of protective gear. While non-owners seem to be aware of the potential health risks related to driving e-scooters, owners express lower perceived safety concerns associated with driving e-scooters.

\section{Conclusion}

The study at hand is the first to examine consumers' perception of e-scooters in a quantitative setting. Factors influencing participants' intention to use e-scooters were investigated. Findings suggest that e-scooters are primarily viewed as entertainment rather than a significant mode of transportation. Evidence for e-scooters' potential to replace ecologically harmful vehicles such as cars is rather weak, and could only be found for short-distance trips $(<2 \mathrm{~km})$. The primary alternative respondents intend to replace is walking. Hence in total, environmentally damaging transportation modes such as driving may be maintained, and the eco-friendly alternative of walking is superseded. Widespread e-scooter usage thus might add to the overall ecological damage as opposed to offering a remedy.

Further, perceptions of risk were evaluated rather low, indicating that providers and policymakers need to elucidate e-scooter riding's hazards, and may enforce wearing protective gear while riding. We also found evidence that important aspects within e-scooters' economic network, some of which may undermine their sustainability claims - namely safety concerns, environmental pollution caused by damaged and dumped vehicles, and the precarious work contracts of 'juicers' - are only mentioned by very few respondents. Hence, the majority of participants are likely unaware of e-scooters' potential adverse impacts. Consequently, increasing experience and coverage of e-scooters may influence the vehicles' image among road users and shift their perceptions towards a more critical perspective. However, it needs to be noticed that these statements were provided voluntarily in a free-format question, and participants may have opted not to make use of this response opportunity even when knowing about the issues. Still, the very small number of answers makes one wonder whether e-scooters' challenges may be assumed to be prominent among many road users.

As for all scientific studies, a number of limitations need to be addressed. First, all measures were based on self-reports, which may lead to social desirability biases regarding behavior in traffic and environmental concerns in the way that respondents may have scored higher than 
what would be the reality. Second, sampling was carried out by acquiring public transportation services as project partners and asking them to spread the questionnaire on their social media accounts. Consequently, consumers that are particularly interested in transportation topics and, as such, regularly read and follow these services' social media content may be overrepresented. Third, sampling was conducted in Germany, and findings may not be directly applicable to settings with significantly different transport infrastructure. However, results of consumers favoring e-scooters for their entertainment potential and relief from walking match extant research from other regional and cultural contexts, and may be generalized to other settings.

Our study provides several opportunities for future research. The model's explanatory power may be tested in other regional and cultural contexts to gain insights into commonalities and distinctions regarding the choice of transportation mode, and drivers of intention to use e-scooters. Additional variables may be added to provide more context-sensitivity, i.e., both factors and moderators. Shortcomings of self-report measurement may be addressed via observational methods. Our research revealed significant differences in the perception of e-scooters between owners and non-owners (see Table 2), stressing the need to analyze consumers based on ownership (James et al., 2019) for deriving distinct implications. Differences between those two groups appeared to be smaller within our model, which might be caused by the rather small number of owners and the in contrast larger, potentially more heterogeneous non-owner group (see Table 6). Future research may conduct a dedicated examination of this segmentation and seek to draw a more balanced sample.

(Appendices available on request.) 


\section{References}

Ajzen, H., Fishbein, M., 1980. Understanding attitudes and predicting social behavior. Prentice-Hall, Englewood Cliffs, New Jersey.

Ajzen, I., 1991. The theory of planned behavior. Organizational behavior and human decision processes 50, 179211.

Allem, J.-P., Majmundar, A., 2019. Are electric scooters promoted on social media with safety in mind? A case study on Bird's Instagram. Preventive medicine reports 13, 62-63. 10.1016/j.pmedr.2018.11.013.

Armstrong, J.S., Overton, T.S., 1977. Estimating Nonresponse Bias in Mail Surveys. Journal of marketing research 14, 396. 10.2307/3150783.

Badeau, A., Carman, C., Newman, M., Steenblik, J., Carlson, M., Madsen, T., 2019. Emergency department visits for electric scooter-related injuries after introduction of an urban rental program. The American journal of emergency medicine 37, 1531-1533. 10.1016/j.ajem.2019.05.003.

Beck, S., Barker, L., Chan, A., Stanbridge, S., 2019. Emergency department impact following the introduction of an electric scooter sharing service. Emergency medicine Australasia.

Benbasat, I., Barki, H., 2007. Quo vadis TAM? JAIS 8, 211-218. 10.17705/1jais.00126.

Burton-Jones, A., Straub, D.W., 2006. Reconceptualizing System Usage: An Approach and Empirical Test. Information Systems Research 17, 228-246. 10.1287/isre.1060.0096.

Che, M., Lum, K.M., Wong, Y.D., 2020. Users' attitudes on electric scooter riding speed on shared footpath: A virtual reality study. International Journal of Sustainable Transportation 1, 1-10. $10.1080 / 15568318.2020 .1718252$.

Cherry, C.R., Weinert, J.X., Xinmiao, Y., 2009. Comparative environmental impacts of electric bikes in China. Transportation Research Part D: Transport and Environment 14, 281-290. 10.1016/j.trd.2008.11.003.

Choron, R.L., Sakran, J.V., 2019. The Integration of Electric Scooters: Useful Technology or Public Health Problem? American journal of public health 109, 555-556. 10.2105/AJPH.2019.304955.

Cordera, R., dell'Olio, L., Ibeas, A., Ortúzar, J.d.D., 2019. Demand for environmentally friendly vehicles: A review and new evidence. International Journal of Sustainable Transportation 13, 210-223. 10.1080/15568318.2018.1459969.

Davis, F.D., 1989. Perceived usefulness, perceived ease of use, and user acceptance of information technology. MIS quarterly, 319-340.

Degele, J., Gorr, A., Haas, K., Kormann, D., Krauss, S., Lipinski, P., Tenbih, M., Koppenhoefer, C., Fauser, J., Hertweck, D., 2018. Identifying E-Scooter Sharing Customer Segments Using Clustering, in: Conference proceedings, ICE/IEEE ITMC 2018. 2018 IEEE International Conference on Engineering, Technology and Innovation (ICE/ITMC) : Stuttgart 17.06.-20.06.18. 2018 IEEE International Conference on Engineering, Technology and Innovation (ICE/ITMC), Stuttgart. 6/17/2018 - 6/20/2018. IEEE, Piscataway, NJ, pp. 1-8.

Dunlap, R.E., van Liere, K.D., Mertig, A.G., Jones, R.E., 2000. New Trends in Measuring Environmental Attitudes: Measuring Endorsement of the New Ecological Paradigm: A Revised NEP Scale. J Social Isssues 56, 425-442. 10.1111/0022-4537.00176.

Elkington, J., 1998. Partnerships from cannibals with forks: The triple bottom line of $21^{\text {st }}$-century business. Environmental quality management $8,37-51$.

Fang, S.-C., Chang, I.-C., Yu, T.-Y., 2015. Assessment of the behavior and characteristics of electric scooter use on islands. Journal of Cleaner Production 108, 1193-1202. 10.1016/j.jclepro.2015.07.095.

Ferber, R., 1948. The Problem of Bias in Mail Returns: A Solution. Public Opinion Quarterly 12, 669. $10.1086 / 266009$. 
Fishbein, M., Ajzen, I., 1975. Belief, attitude, intention, and behavior: An introduction to theory and research. Addison-Wesley, Reading, Massachusetts.

Fornell, C., Larcker, D.F., 1981. Evaluating structural equation models with unobservable variables and measurement error. Journal of marketing research 18, 39-50.

GfK, 2019. Was sind Ihrer Meinung nach die größten Herausforderungen in Hinblick auf die Mobilität der Zukunft? [What are the biggest challenges for mobility?]. Retrieved from https://de.statista.com/statistik/daten/studie/1069304/umfrage/umfrage-zu-den-herausforderungen-der-mobilitaet-der-zukunft/.

Gössling, S., 2020. Integrating e-scooters in urban transportation: Problems, policies, and the prospect of system change. Transportation Research Part D: Transport and Environment 79, 102230.

Gössling, S., Cohen, S., 2014. Why sustainable transport policies will fail: EU climate policy in the light of transport taboos. Journal of Transport Geography 39, 197-207. 10.1016/j.jtrangeo.2014.07.010.

Guerra, E., 2019. Electric vehicles, air pollution, and the motorcycle city: A stated preference survey of consumers' willingness to adopt electric motorcycles in Solo, Indonesia. Transportation Research Part D: Transport and Environment 68, 52-64. 10.1016/j.trd.2017.07.027.

Hair, J.F., Ringle, C.M., Sarstedt, M., 2011. PLS-SEM: Indeed a Silver Bullet. Journal of Marketing Theory and Practice 19, 139-152. 10.2753/MTP1069-6679190202.

Hair, J.F., Risher, J.J., Sarstedt, M., Ringle, C.M., 2019. When to use and how to report the results of PLS-SEM. European Business Review.

Hardt, C., Bogenberger, K., 2019. Usage of e-Scooters in Urban Environments. Transportation Research Procedia 37, 155-162. 10.1016/j.trpro.2018.12.178.

Haustein, S., Jensen, A.F., 2018. Factors of electric vehicle adoption: A comparison of conventional and electric car users based on an extended theory of planned behavior. International Journal of Sustainable Transportation 12, 484-496. 10.1080/15568318.2017.1398790.

Henseler, J., 2012. PLS-MGA: A non-parametric approach to partial least squares-based multi-group analysis. In: Challenges at the interface of data analysis, computer science, and optimization. Springer, pp. 495-501.

Henseler, J., Chin, W.W., 2010. A Comparison of Approaches for the Analysis of Interaction Effects Between Latent Variables Using Partial Least Squares Path Modeling. Structural Equation Modeling: A Multidisciplinary Journal 17, 82-109. 10.1080/10705510903439003.

Henseler, J., Ringle, C.M., Sarstedt, M., 2015. A new criterion for assessing discriminant validity in variancebased structural equation modeling. Journal of the academy of marketing science 43, 115-135.

Hollingsworth, J., Copeland, B., Johnson, J.X., 2019. Are e-scooters polluters? The environmental impacts of shared dockless electric scooters. Environ. Res. Lett. 14, 84031. 10.1088/1748-9326/ab2da8.

Hughner, R.S., McDonagh, P., Prothero, A., Shultz, C.J., Stanton, J., 2007. Who are organic food consumers? A compilation and review of why people purchase organic food. Journal of Consumer Behaviour: An International Research Review 6, 94-110.

James, O., Swiderski, J., Hicks, J., Teoman, D., Buehler, R., 2019. Pedestrians and E-Scooters: An Initial Look at E-Scooter Parking and Perceptions by Riders and Non-Riders. Sustainability 11, 5591. $10.3390 / \mathrm{su} 11205591$.

Jenn, A., Laberteaux, K., Clewlow, R., 2018. New mobility service users' perceptions on electric vehicle adoption. International Journal of Sustainable Transportation 12, 526-540. 10.1080/15568318.2017.1402973.

Jöreskog, K.G., 1971. Simultaneous factor analysis in several populations. Psychometrika 36, 409-426.

Kim, J., Choi, K., Kim, S., Fujii, S., 2017. How to promote sustainable public bike system from a psychological perspective? International Journal of Sustainable Transportation 11, 272-281. 10.1080/15568318.2016.1252450. 
Kobayashi, L.M., Williams, E., Brown, C.V., Emigh, B.J., Bansal, V., Badiee, J., Checchi, K.D., Castillo, E.M., Doucet, J., 2019. The e-merging e-pidemic of e-scooters. Trauma surgery \& acute care open 4, e000337. 10.1136/tsaco-2019-000337.

Kock, N., 2015. Common method bias in PLS-SEM: A full collinearity assessment approach. International Journal of e-Collaboration (ijec) 11, 1-10.

Kock, N., Hadaya, P., 2018. Minimum sample size estimation in PLS-SEM: The inverse square root and gammaexponential methods. Information Systems Journal 28, 227-261.

Kollmuss, A., Agyeman, J., 2002. Mind the gap: why do people act environmentally and what are the barriers to pro-environmental behavior? Environmental education research 8, 239-260.

Kroesen, M., 2017. To what extent do e-bikes substitute travel by other modes? Evidence from the Netherlands. Transportation Research Part D: Transport and Environment 53, 377-387. 10.1016/j.trd.2017.04.036.

Lee, K., 2008. Opportunities for green marketing: young consumers. Mrkting Intelligence \& Plan 26, 573-586. 10.1108/02634500810902839.

Liew, Y.K., Wee, C.P.J., Pek, J.H., 2020. New peril on our roads: a retrospective study of electric scooter-related injuries. Singapore medical journal 61, 92-95. 10.11622/smedj.2019083.

Liu, C., Lin, Z., 2017. How uncertain is the future of electric vehicle market: Results from Monte Carlo simulations using a nested logit model. International Journal of Sustainable Transportation 11, 237-247. 10.1080/15568318.2016.1248583.

Martínez-Díaz, M., Soriguera, F., Pérez, I., 2018. Technology: A Necessary but Not Sufficient Condition for Future Personal Mobility. Sustainability 10, 4141. 10.3390/su10114141.

Masoud, M., Elhenawy, M., Almannaa, M.H., Liu, S.Q., Glaser, S., Rakotonirainy, A., 2019. Heuristic Approaches to Solve E-Scooter Assignment Problem. IEEE Access 7, 175093-175105. 10.1109/ACCESS.2019.2957303.

McKenzie, G., 2019. Spatiotemporal comparative analysis of scooter-share and bike-share usage patterns in Washington, D.C. Journal of Transport Geography 78, 19-28. 10.1016/j.jtrangeo.2019.05.007.

McKenzie, G., 2020. Urban mobility in the sharing economy: A spatiotemporal comparison of shared mobility services. Computers, Environment and Urban Systems 79, 101418. 10.1016/j.compenvurbsys.2019.101418.

Moreau, H., Jamblinne Meux, L. de, Zeller, V., D’Ans, P., Ruwet, C., Achten, W.M.J., 2020. Dockless EScooter: A Green Solution for Mobility? Comparative Case Study between Dockless E-Scooters, Displaced Transport, and Personal E-Scooters. Sustainability 12, 1803. 10.3390/su12051803.

Morton, C., Anable, J., Nelson, J.D., 2017. Consumer structure in the emerging market for electric vehicles: Identifying market segments using cluster analysis. International Journal of Sustainable Transportation 11, 443-459. 10.1080/15568318.2016.1266533.

Nisson, P.L., Ley, E., Chu, R., 2020. Electric Scooters: Case Reports Indicate a Growing Public Health Concern. American journal of public health 110, 177-179. 10.2105/AJPH.2019.305499.

Nysveen, H., 2005. Intentions to Use Mobile Services: Antecedents and Cross-Service Comparisons. Journal of the academy of marketing science 33, 330-346. 10.1177/0092070305276149.

Osswald, S., Wurhofer, D., Trösterer, S., Beck, E., Tscheligi, M., 2012. Predicting information technology usage in the car: towards a car technology acceptance model. Proceedings of the $4^{\text {th }}$ International Conference on Automotive User Interfaces and Interactive Vehicular Applications.

Permut, S.E., Michel, A.J., Joseph, M., 1976. The researcher's sample: A review of the choice of respondents in marketing research. Journal of Marketing Research 12, 278-283.

Pham, T.T., Kuo, T.-C., Tseng, M.-L., Tan, R.R., Tan, K., Ika, D.S., Lin, C.J., 2019. Industry 4.0 to Accelerate the Circular Economy: A Case Study of Electric Scooter Sharing. Sustainability 11, 6661. $10.3390 / \mathrm{su} 11236661$. 
Pickett-Baker, J., Ozaki, R., 2008. Pro-environmental products: marketing influence on consumer purchase decision. Journal of consumer marketing.

Portland Bureau of Transportation, 2018. E-Scooter Findings Report. https://www.portlandoregon.gov/transportation/article/709719.

Puzio, T.J., Murphy, P.B., Gazzetta, J., Dineen, H.A., Savage, S.A., Streib, E.W., Zarzaur, B.L., 2020. The electric scooter: A surging new mode of transportation that comes with risk to riders. Traffic injury prevention 21, 175-178. 10.1080/15389588.2019.1709176.

Rezvani, Z., Jansson, J., Bodin, J., 2015. Advances in consumer electric vehicle adoption research: A review and research agenda. Transportation Research Part D: Transport and Environment 34, 122-136. 10.1016/j.trd.2014.10.010.

Sang, Y.-N., Bekhet, H.A., 2015. Modelling electric vehicle usage intentions: an empirical study in Malaysia. Journal of Cleaner Production 92, 75-83. 10.1016/j.jclepro.2014.12.045.

Sarstedt, M., Henseler, J., Ringle, C.M., 2011. Multi-Group Analysis in Partial Least Squares (PLS) Path Modeling: Alternative Methods and Empirical Results. Advances in international marketing 22, 195-218.

Seebauer, S., 2015. Why early adopters engage in interpersonal diffusion of technological innovations: An empirical study on electric bicycles and electric scooters. Transportation Research Part A: Policy and Practice 78, 146-160. 10.1016/j.tra.2015.04.017.

She, Z.-Y., Qing Sun, Ma, J.-J., Xie, B.-C., 2017. What are the barriers to widespread adoption of battery electric vehicles? A survey of public perception in Tianjin, China. Transport Policy 56, 29-40. 10.1016/j.tranpol.2017.03.001.

Sikka, N., Vila, C., Stratton, M., Ghassemi, M., Pourmand, A., 2019. Sharing the sidewalk: A case of E-scooter related pedestrian injury. The American journal of emergency medicine 37, 1807.e5-1807.e7. 10.1016/j.ajem.2019.06.017.

Singh, N., Matsuo, H., 2004. Measuring cultural adaptation on the web: a content analytic study of US and Japanese web sites. Journal of Business Research 57, 864-872.

Sovacool, B.K., Abrahamse, W., Zhang, L., Ren, J., 2019. Pleasure or profit? Surveying the purchasing intentions of potential electric vehicle adopters in China. Transportation Research Part A: Policy and Practice 124, 69-81. 10.1016/j.tra.2019.03.002.

Sun, H., 2012. Understanding user revisions when using information system features: Adaptive system use and triggers. MIS quarterly, 453-478.

Sun, Q., Feng, T., Kemperman, A., Spahn, A., 2020. Modal shift implications of e-bike use in the Netherlands: Moving towards sustainability? Transportation Research Part D: Transport and Environment 78, 102202. 10.1016/j.trd.2019.102202.

Tait, P., Saunders, C., Dalziel, P., Rutherford, P., Driver, T. and Guenther, M. 2020. Comparing generational preferences for individual components of sustainability schemes in the Californian wine market. Applied Economics Letters 27, 1091-1095.

Tezer, A., Bodur, H.O., 2019. The Greenconsumption Effect: How Using Green Products Improves Consumption Experience. Journal of Consumer Research.

Tuncer, S., Laurier, E., Brown, B., Licoppe, C., 2020. Notes on the practices and appearances of e-scooter users in public space. Journal of Transport Geography 85, 102702. 10.1016/j.jtrangeo.2020.102702.

van der Heijden, H., 2004. User acceptance of hedonic information systems. MIS quarterly, 695-704.

VDV (Association of German Transport Companies). https://www.vdv.de/english_2.aspx.

Venkatesh, V., Davis, F., Morris, M., 2007. Dead Or Alive? The Development, Trajectory And Future Of Technology Adoption Research. JAIS 8, 267-286. 10.17705/1jais.00120. 
Venkatesh, V., Morris, M.G., Davis, G.B., Davis, F.D., 2003. User acceptance of information technology: Toward a unified view. MIS quarterly, 425-478.

Venkatesh, V., Thong, J.Y.L., Xu, X., 2012. Consumer acceptance and use of information technology: extending the unified theory of acceptance and use of technology. MIS quarterly, 157-178.

Wang, Y.-W., 2007. An optimal location choice model for recreation-oriented scooter recharge stations. Transportation Research Part D: Transport and Environment 12, 231-237. 10.1016/j.trd.2007.02.002.

Weiss, M., Dekker, P., Moro, A., Scholz, H., Patel, M.K., 2015. On the electrification of road transportation - A review of the environmental, economic, and social performance of electric two-wheelers. Transportation Research Part D: Transport and Environment 41, 348-366. 10.1016/j.trd.2015.09.007.

Woodside, A.G., 2013. Moving beyond multiple regression analysis to algorithms: Calling for adoption of a paradigm shift from symmetric to asymmetric thinking in data analysis and crafting theory. Elsevier.

Xu, J., Shang, S., Yu, G., Qi, H., Wang, Y., Xu, S., 2016. Are electric self-balancing scooters safe in vehicle crash accidents? Accident; analysis and prevention 87, 102-116. 10.1016/j.aap.2015.10.022.

Yadav, R. and Pathak, G.S. 2016. Young consumers' intention towards buying green products in a developing nation: Extending the theory of planned behavior. Journal of Cleaner Production 135, 732-739.

Yang, H., Ma, Q., Wang, Z., Cai, Q., Xie, K., Di Yang, 2020. Safety of micro-mobility: Analysis of E-Scooter crashes by mining news reports. Accident Analysis \& Prevention 143, 105608.

YouGov, 2019. Sehen Sie E-Scooter für sich persönlich eher als Möglichkeit, sich umweltfreundlich fortzubewegen oder ist der E-Scooter für Sie ein Fortbewegungsmittel zum Vergnügen? [Do you perceive e-scooters as an environmentally friendly mode of transportation or rather a vehicle for entertainment purposes?]. Retrieved from https://yougov.de/opi/surveys/results/\#/survey/8a752e0f-a158-11e9-8fc2-83a62feecb3c/question/f3181755-a162-11e9-bd83-c1c26ae0f2f3/gender.

Zagorskas, J., Burinskienė, M., 2020. Challenges Caused by Increased Use of E-Powered Personal Mobility Vehicles in European Cities. Sustainability 12, 273. 